\section{A dimensão da Infectologia}

Infectology dimension

\section{Senhor Editor:}

É claramente perceptível crescente intenção de alguns profissionais da área médica no sentido de valorizar e agrupar de maneira muito expressiva, incluindo até 0 caráter de exclusividade, todos os tipos de ações congêneres sob o rótulo de Infectologia. Trata-se de desejo, mais do que opinião, merecedor de atenção e, logicamente, de comentários.

As tarefas atinentes a variados aspectos relativos às doenças infecciosas e parasitárias, bastante incidentes no Brasil, em Disciplinas de Faculdades de Medicina e em Serviços públicos ou privados tradicionalmente têm diferentes denominações, segundo convicções e critérios de seus idealizadores. Lembramo-nos de algumas: infectuosas e tropicais; infectuosas e parasitárias; infecciosas e parasitárias; infecciosas; transmissíveis. Sem dúvida, tudo depende das missões a cumprir, de características de ambientes específicos e de pareceres respeitáveis.

Hoje é evidente a ojeriza que uns adeptos de mudanças, como decorrência de causas que precisam esclarecer, pela expressão tropical, que interpretam como coisa antiquada e também até pejorativa. Apegados ao que julgam ser modernidades, desvalorizam os sucessos e interesses de pesquisadores dedicados às enfermidades tropicais, sendo um bom número deles pioneiros no contexto científico nacional ou internacional. É irrelevante pretender esmiuçar profundamente 0 que corresponde com correção a tropical. 0 que vale, de fato, é 0 êxito e 0 brilhante trabalho executado por seus baluartes.

Apesar de veteranos, julgamos melhor não sermos personalistas e buscamos em dicionários o significado de Infectologia. É 0 ramo da Medicina que se ocupa do estudo das doenças infecciosas. Vale destacar a palavra estudo e notar que se trata de algo englobador de muito ampla gama de finalidades, determinante de análise.

Como curiosidade, mencionando alguns exemplos, registramos uma especulação, concernente à possibilidade de Adolfo Lutz, Aluízio Prata, Carlos Chagas, Carlos da Silva Lacaz, Evandro Chagas, Emmanuel Dias, José Rodrigues Coura, José Rodrigues da Silva, João Carlos Pinto Dias, Pedro Luiz Tauil, Pirajá da Silva, Samuel Barnsley Pessôa, Vanize de Oliveira Macedo, Zigman Brener e Zilton de Araújo Andrade serem tidos como infectologistas e não tropicalistas.

№ contexto de diversas especialidades estão enfermidades causadas por microrganismos. Ilustrações: sinusite bacteriana (Otorrinolaringologia); infecção por Helicobacter pylori (Gastrenterologia); tuberculose (Tisiologia); prostatite aguda (Urologia); infecção no trato urinário (Nefrologia); abscesso cerebral (Neurologia); abscesso pós-intervenção cirúrgica (Cirurgia) ; toxoplasmose ocular (Oftalmologia); vulvovaginite infecciosa (Ginecologia); infecção congênita (Obstetrícia); osteomielite (Ortopedia); endocardite infecciosa (Cardiologia); infecção em imunodeprimido (várias especialidades); infecção pós-transplante de órgão (várias especialidades). Impõe-se, então, saber se os que prestam atendimento nessas circunstâncias são infectologistas.

Caso a intenção dos que almejam consagrar a denominação Infectologia como única, soberana, exclusiva e indivisível, haverá obrigação de mudar o título de órgãos consagrados: Instituto de Medicina Tropical de São Paulo para Instituto de Infectologia de São Paulo; Departamento de Moléstias Infecciosas e Parasitárias, da Faculdade de Medicina da Universidade de São Paulo, para Departamento de Infectologia, da Faculdade de Medicina da Universidade de São Paulo; Instituto de Medicina Tropical da Amazônia para Instituto de Infectologia da Amazônia; Sociedade Brasileira de Medicina Tropical para Sociedade Brasileira de Infectologia; Clínica Especializada em Doenças Infecciosas e Parasitárias e em Imunizações (CEDIPI, São Paulo) para Clínica de Infectologia e de Imunizações; Departamento de Medicina Tropical, da Fundação Oswaldo Cruz, para Departamento de Infectologia, da Fundação Oswaldo Cruz; Fundação de Medicina Tropical do Tocantins para Fundação de Infectologia do Tocantins; Disciplina de Doenças Transmissíveis, do Centro de Ciências da Saúde da Universidade Estadual de Londrina, para Disciplina de Infectologia, do Centro de Ciências da Saúde da Universidade Estadual de Londrina; Curso de Pós-Graduação em Medicina Tropical, da Faculdade de Medicina da Universidade Federal de Minas Gerais, para Curso de Pós-Graduação em Infectologia, da Faculdade de Medicina da Universidade Federal de Minas Gerais. São apenas alguns exercícios, dignos de ponderações.

Somos adeptos da qualificação doenças transmissíveis para nortear trabalhos assistenciais, didáticos e científicos no panorama das questões atinentes a infecções e parasitoses, em setores universitários, além de outros correlatos em Serviços públicos ou privados. É conduta coerente com limites bem definidos, revelando atenção voltada a enfermidades claramente catalogadas, inexistindo comprometimentos concernentes a especialidades diferentes que acolhem múltiplas variedades de infecções. Outrossim, possibilita adoção de cuidados quando há risco de contágio, prevendo-se adequado isolamento, protetor da instituição e da comunidade. Sempre defendemos esse rótulo e fomos geralmente acatados. Agora vemos opositores a isso, em virtude de motivos que gostaríamos não fossem contestações personalísticas, figurando porém como mais aceitável apresentar respaldos convincentes.

Se Infectologia, para seus propositores, é referência única, soberana, exclusiva e indivisível convirá que conheçamos a exata dimensão dela para, pura e simplesmente, não ficar necessário discutível confronto com outras designações. Convirá igualmente mostrar que não há influência de caprichos, busca de imponderável notoriedade e nexo com mercado de trabalho.

\section{Vicente Amato Neto ${ }^{1}$ e Jacyr Pasternack ${ }^{2}$}

\footnotetext{
1. Laboratório de Investigação Médica Parasitologia do Departamento de Moléstias Infecciosas e Parasitárias do Hospital das Clínicas da Faculdade de Medicina da Universidade de São Paulo, São Paulo, SP. 2. Hospital Israelita Albert Einstein, São Paulo, SP.
} 